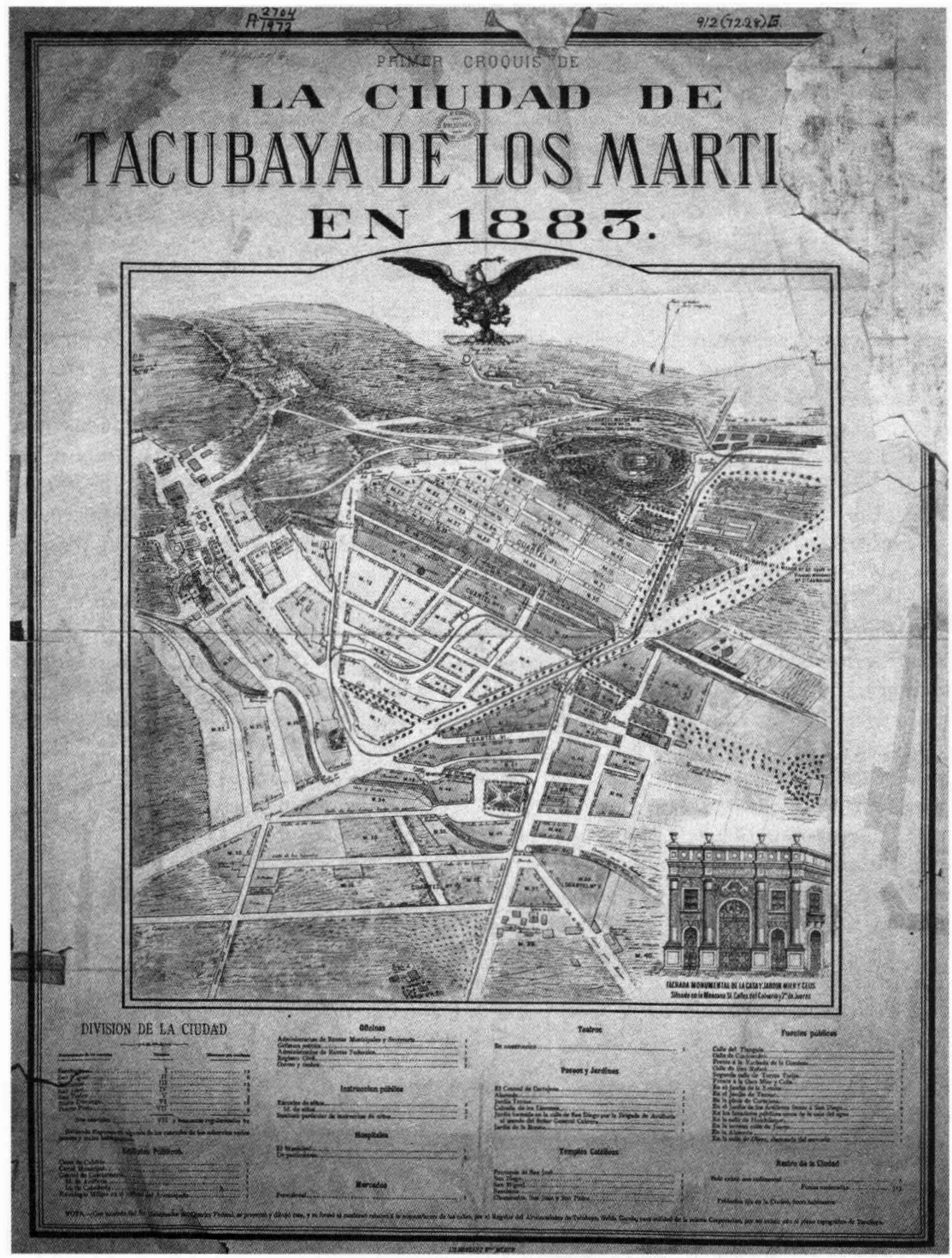




\section{Lillian Briseño Senosiain}

Doctora en Historia por la UNAM. Profesora-investigadora asociado c en CIESAS, con adscripción a CIESAS-Occidente. Ha desempeñado diversos trabajos académicos y administrativos en el Instituto de Investigaciones Dr. José María Luis Mora, en el ConACulTa y en la Coordinación de Asesores del Rector de la uNAM, entre otros. Su tema ha sido el siglo XIX mexicano, abarcando en sus últimas investigaciones hasta el porfiriato. Entre sus publicaciones destacan: Obras completas de José María Luis Mora; Valentín Gómez Farías y su lucha por el federalismo; La independencia boy, textos de su bistoria.

\section{Resumen}

Las fiestas del Centenario de la Independencia se significaron por dar al presidente Porfirio Díaz el pretexto ideal para mostrar al mundo todos los avances que México había alcanzado bajo su mandato. Algunos de los más importantes fueron los que lograron la modernización del país en el plano tecnológico y científico: la extensión de los sistemas de comunicación y transporte, seguidos de la introducción de la electricidad, serían sin duda algunos de los más relevantes. Por lo que respecta al alumbrado público eléctrico, las conmemoraciones septembrinas en la capital permiten ver la evolución que siguió el proceso de iluminación artificial, como una muestra de los progresos que iba alcanzando el país en este sector año con año, a tal grado que, para 1910, la ciudad de México resplandecería como nunca, impresionando con su luz a propios y extraños y logrando que esta urbe fuera, en el decir de muchos, la mejor iluminada del mundo.

Palabras clave:

Luz, electricidad, centenario, noche, modernización, porfiriato.

\section{Abstract}

The Centenary of Independence celebrations constituted an ideal opportunity for Porfirio Diaz to show the world the progress Mexico had made under his mandate. Some of the most important of the improvements contributed to the modernization of the country at the technological and scientific level, such as the extension of the communications and transport systems, followed by the introduction of electricity. As regards public electric lighting, the Independence Day celebrations in September in the capital enabled the public to see the evolution of artificial lighting as an example of the progress the country was achieving in this sector every year. In 1910, Mexico City shone like never before, impressing locals and foreigners alike and becoming the world's best-lit city, in many people's view.

Key words:

Light, electricity, centenary, modernization, era of Porfirio Díaz.

Fecha de recepción: octubre de 2003

Fecha de aceptación: marzo de 2004 


\title{
La fiesta de luz en la ciudad de México. El alumbrado eléctrico en el Centenario
}

\author{
Lillian Briseño Senosiain
}

\section{0: LA MODERNIZACIÓN}

$\mathbf{L}$ a ciudad de México, en el año del primer centenario de su independencia, reunía quizá todas las características que una urbe moderna podía presentar. Contaba con una población cercana a los 500000 habitantes, mismos que convivían de manera cotidiana en un área construida de 40.5 kilómetros cuadrados. ${ }^{1}$ En algunas de sus zonas -las más elegantes y céntricas- tenía calles asfaltadas, alumbrado eléctrico, un sistema de drenaje recién inaugurado y redes de telégrafo, teléfono y tranvías. ${ }^{2}$ Estos últimos

1 "Entre 1856 y 1910 el área construida de la ciudad pasó de 8.5 kilómetros cuadrados a 40.5 [...] y el número de colonias establecidas en la municipalidad de México, para el periodo 1858-1910, probablemente rebasó las 35." Véase Rodríguez, Experiencia, 1996, p. 92.

${ }^{2}$ Cabe aclarar que si bien el gobierno se esforzó por modernizar toda la capital, los beneficios se dejaron sentir, mucho más, en la zona céntrica y el suroeste de la ciudad. De esta manera se urbanizaron, preferentemente, avenida Reforma y algunas colonias de grandes pretensiones como la Juárez, la Cuauhtémoc, la Roma y la Condesa. Para la clase media se crearon la San Rafael y la Limantour, mientras que los trabajadores proletarios se instalaron en el noroeste en las colonias Santa María, Guerrero, Morelos, La Bolsa, Díaz de León, Rastro, Maza y Valle Gómez. cruzaban la capital integrándola y comunicándola tanto al interior como al exterior, dando lugar a un nuevo paisaje urbano en el que los cables, los postes y las vías de los trolleys eran algo común. Ellos eran parte de un escenario que proyectaba imágenes increỉbles que, como en el teatro, escondía tras de sí otra realidad, muy distinta a la que se ofrecía al simple espectador.

En la capital, algunos automóviles se abrían paso entre los cada vez menos comunes carruajes, que con nombres como "simones", "landós" o "victorias", iban y venían por esta ciudad cosmopolita que era, sin duda, uno de los mayores orgullos del presidente Díaz. Para 1910, el paseo obligado conducía a la elite porfirista por las calles de Plateros y San Francisco, ${ }^{3}$ continuaba por avenida Juárez y pasaba por la Alameda hasta llegar al cruce con la recién engalanada avenida Reforma, en la cual se podía disfrutar de las maravillosas estatuas de El Caballito, Colón y Cuauhtémoc que ocupaban sendas glorietas de esta importante arteria. Remataba el paseo en el Castillo de Chapultepec, no sin antes disfrutar del imponente y soberbio Monumento de la Independencia,

${ }^{3}$ Las dos conforman hoy lo que es la avenida Madero. 
que con su Victoria Alada coronaba los cielos de la ciudad y cuya inauguración el 16 de septiembre fue quizá una de las más esperadas y que mayor atención atrajo durante las fiestas del Centenario.

En este año, la moderna ciudad de México ofrecía a su población múltiples atractivos: restaurantes (fondas elegantes como se les llegó a llamar), grandes almacenes, teatros, bulevares, nuevas colonias y el bullicio de una gran metrópoli, todo lo cual se encontraba resaltado por un marco de luz -de luz eléctrica- único en el planeta, según presumían los diarios y las crónicas de aquellos años.

Uno de los objetivos porfiristas para aquel año de 1910 era que los ojos del mundo se fijaran en este país que unos cuantos años antes se debatía aún en medio de guerras civiles, amenazas extranjeras y una bancarrota que acompañó a México desde el momento de su independencia hasta hacía apenas tres lustros, cuando se logró superar el déficit público. Gracias al poder hegemónico que desplegaba el gobierno de Díaz y a las inversiones en vías de comunicación, precedidas por los ferrocarriles, esta nación otrora desintegrada política y geográficamente mostraba ahora una nueva cara, como un país renovado, unido, comunicado y en franco desarrollo económico. Eso era al menos en apariencia lo que se pretendía mostrar y con ese propósito había trabajado el presidente desde hacía varios años.

Irónicamente, sin embargo, 1910 es poco recordado como el año en el que el país acariciaba la gloria y aprovechaba las fiestas del Centenario para exhibir al mundo el desarrollo político, económico y tecnológico alcanzados; se lo recuerda, más bien, como la fecha en que dio inicio la revolución. Asimismo, pocos saben que
México culminaba entonces el proceso de modernización proyectado y desarrollado desde años atrás, logrando una capacidad impresionante en la generación de energía eléctrica, uno de los símbolos de esta modernización y factor determinante para desarrollar la industria nacional.

En efecto, desde que se hicieron los primeros ensayos para introducir esta energía hasta que Porfirio Díaz decidió apostar de manera franca por la electrificación del país y su final aplicación a la extracción, la industria, las comunicaciones, el alumbrado y uso doméstico pasaron casi 30 años, durante los cuales este sector se convirtió en el segundo rubro de mayor inversión en desarrollo de infraestructura del país, sólo por debajo de la destinada a la construcción de los ferrocarriles, que eran considerados como el máximo símbolo del progreso. ${ }^{4}$

Gracias al capital que llegó entonces -proveniente principalmente del extranjero-, ${ }^{5}$ se construyeron las plantas termoeléctricas e hidroeléctricas que a través de torres y cables llevarían corriente a los diferentes puntos del país. México podía presumir al final del porfiriato, en ese emblemático año de 1910 , de poseer una de las más potentes plantas hidroeléctricas

4 "Para 1910, del total estimado de 1200 millones de dólares de la inversión extranjera, 750 [millones] correspondían a las industrias extractivas incluido el petróleo; 200000000 a los ferrocarriles que servían principalmente a la minería; 150000000 a la generación de energía eléctrica, también ligada a las necesidades de la minería; y los 200000000 restantes se invirtieron en la agricultura y ganadería de exportación." Wionczek, Nacionalismo, 1975, p. 5.

5 Las inversiones provenían, en su mayoría, de Estados Unidos, Inglaterra, Francia y Alemania. Para mayor información, véase Ceseña, México, 1973. 
del mundo: la de Necaxa. ${ }^{6}$ La más grande según las fuentes de la época, sólo comparable con la de Búfalo en Estados Unidos, que aprovechaba la caída de las cataratas del Niágara para su generación.

Por lo que respecta a la ciudad de México, ${ }^{7}$ ésta se convirtió en uno de los principales receptores de inversión, a tal grado que, de acuerdo con los documentos de la época, para el cambio de siglo toda ella contaba con alumbrado público eléctrico. Este progreso permitía augurar que para las fiestas del Centenario ${ }^{8}$ se podría contar con una urbe pletórica de luz, radiante de brillo y poseedora de muchos de los adelantos que simbolizaban la modernización y que se entendían también como expresión de civilización: electricidad, industria, automóviles, cinematógrafos,

${ }^{6}$ La planta hidroeléctrica de Necaxa, propiedad de la Mexican Light and Power Co., fue, con toda seguridad, la más grande de toda América Latina. Tuvo un costo de 17000000 de dólares y la capacidad para suministrar 60000 caballos de fuerza a su máxima capacidad. Su construcción se inició en 1903 y en su desarrollo se empleó a cerca de 10000 trabajadores, se transportaron 35000 toneladas de maquinaria, se construyeron $50 \mathrm{~km}$ de carreteras y se inundaron varios pueblos y rancherías. Véase El $\mathrm{Im}$ parcial, 4 de marzo de 1907 y Galarza, Industria, 1941.

7 "Hacia 1910 el crecimiento de la ciudad se había dirigido hacia el suroeste y oeste hasta invadir los municipios de Tacuba y Tacubaya; hacia el norte quedando la ciudad unida (no de manera homogénea) a los municipios de Azcapotzalco y Guadalupe $\mathrm{Hi}$ dalgo; hacia el sur generando un espacio de colonias para grupos de altos ingresos, y en donde ya no se continuó la traza teticular", Huarte, "Política", 1991, p. 55.

${ }^{8}$ Para una mayor abundancia sobre la intención de Díaz de construir una ciudad moderna para las fiestas del Centenario, a imagen y semejanza de París, véase Tenorio, "1910", 1996. bulevares, restaurantes, almacenes, palacios. En el fondo, un halo de presunción y vanidad por parte de Díaz enmarcaba todo este derroche, pues la imagen que proyectara la capital se identificaría plenamente con la del propio presidente, de tal suerte que, si aquélla lograba resplandecer, él también lo haría.

Es por eso que no se escatimaron recursos para su electrificación, y en 1896 se firmó uno de los contratos más importantes en este sentido con la compañía alemana Siemens y Halske. ${ }^{9}$ En una primera etapa, ella se encargó de construir la infraestructura que permitiría extender el alumbrado eléctrico a toda la ciudad; posteriormente se hicieron los arreglos necesarios para facilitar que esta empresa pudiera ofrecer también el servicio a otros sectores como a la industria y el transporte, y a su uso en los edificios públicos y en las casas habitación. ${ }^{10}$ Así pues, la capital

${ }^{9}$ Tras algunos conflictos provocados con la Compañía de Gas y Luz Eléctrica cuyos orígenes se remontan al segundo imperio y que se había encargado del alumbrado público desde entonces, la Compañía de Siemens y Halske dominaría el mercado a partir de 1896 , y dos años después conformaría la Compañía Mexicana de Electricidad. En 1905, la Mexican Light and Power Co. absorbería a las dos anteriores, además de a la Compañía Explotadora de San Ildefonso, y monopolizaría el servicio hasta el final del porfiriato e incluso después.

${ }^{10}$ El camino recorrido para electrificar la capital se puede seguir fácilmente a través de la hemerografía de la época, de las Actas de Cabildo y de los diversos contratos celebrados con las diferentes compañías entre 1881 y 1910 . En ellas podemos encontrar, por ejemplo, noticia y testimonios de los primeros ensayos realizados con luz eléctrica, del monto de las inversiones destinadas al rubro, de cómo se fue creando una legislación ad hoc para esta novedad, y de los miedos y temores que su introducción provocó en 
contaba a principios del siglo Xx con el apoyo presidencial para extender la energía eléctrica a toda la ciudad, con las inversiones necesarias para hacerlo y con el desarrollo tecnológico indispensable para lograrlo.

En las siguientes páginas se analizará cuál fue el desarrollo y el impacto de la electrificación del alumbrado público en la ciudad de México durante las fiestas patrias del porfiriato, a partir del doble significado que tuvo su instalación en la capital: por un lado, la luz como un ejemplo del mundo científico y moderno que se pretendía y, por el otro, la iluminación como expresión estética y festiva de la gran capital.

\section{LA LUZ DEL PROGRESO}

Como parte del afán modernizador del país, la electrificación del mismo se convirtió en un símbolo ostensible del progreso. Si bien las primeras aplicaciones que se dieron en el mundo a la electricidad fueron en la extracción minera y en la industria, tras el descubrimiento de la subdivisión de la luz y del foco incandes-

\footnotetext{
muchos de los mexicanos. Asimismo, la lectura de novelas propias del costumbrismo, realismo y naturalismo fueron fundamentales para una comprensión más humanizada de lo que fue el proceso de electrificación del país. Cada una de estas expresiones nos permite acercarnos a lo que fue una experiencia singular en la historia del país, que da luces sobre cómo recibió la población una de las manifestaciones más claras de su modernización, alterando de paso hábitos y comportamientos seculares, con el correspondiente impacto en la forma de ver y entender su contexto. Para mayor información, véase Briseño, "Particular", 2002.
}

cente por parte de Edison, se logró también su utilización para la iluminación de los espacios públicos o privados. ${ }^{11}$

En el último cuarto del siglo XIX, la aplicación de la electricidad para el alumbrado era lo más "moderno" que existía en el mundo, tanto así que en México se hacían los primeros experimentos de manera paralela a los que se llevaban a cabo en otros países como Inglaterra, Alemania o Estados Unidos, en donde también se realizaban ensayos para valorar la efectividad de esta fuente de energía en la iluminación nocturna en sustitución del gas.

Por otro lado, cabe recordar que de acuerdo con la filosofía positivista dominante en la época se consideraba que la humanidad había llegado ya a un nuevo estadio en el que la ciencia dictaba el rumbo a seguir. En ese entorno, la electricidad ocupaba un papel protagónico, pues ¿acaso podía haber una expresión más elocuente del avance científico que la aplicación de la electricidad? Esa energía era capaz de mover y hacer funcionar casi todo, lo mismo los motores de las fábricas que los de los trolleys, los focos o los electrodomésticos, sin olvidar su aplicación terapéutica para el tratamiento de muchas enfermedades.

Así pues, en la mentalidad de los porfiristas educados bajo los principios del

${ }^{11 .}$ La luz incandescente (el foco eléctrico) se descubrió hacia 1879 , pero ya desde antes existían lámparas con una gran potencia que, a manera de reflectores y conectadas a una planta propia, servían para iluminar grandes espacios. Su luz, sin embargo, resultaba muy molesta a la vista e inútil para lugares más reducidos, lo que llevó a que muchos científicos se avocaran a la tarea de subdividir esa luz, siendo Edison el más exitoso. Véase Bowers, Lenghtening, 1998. 


\section{SECUENCIG}

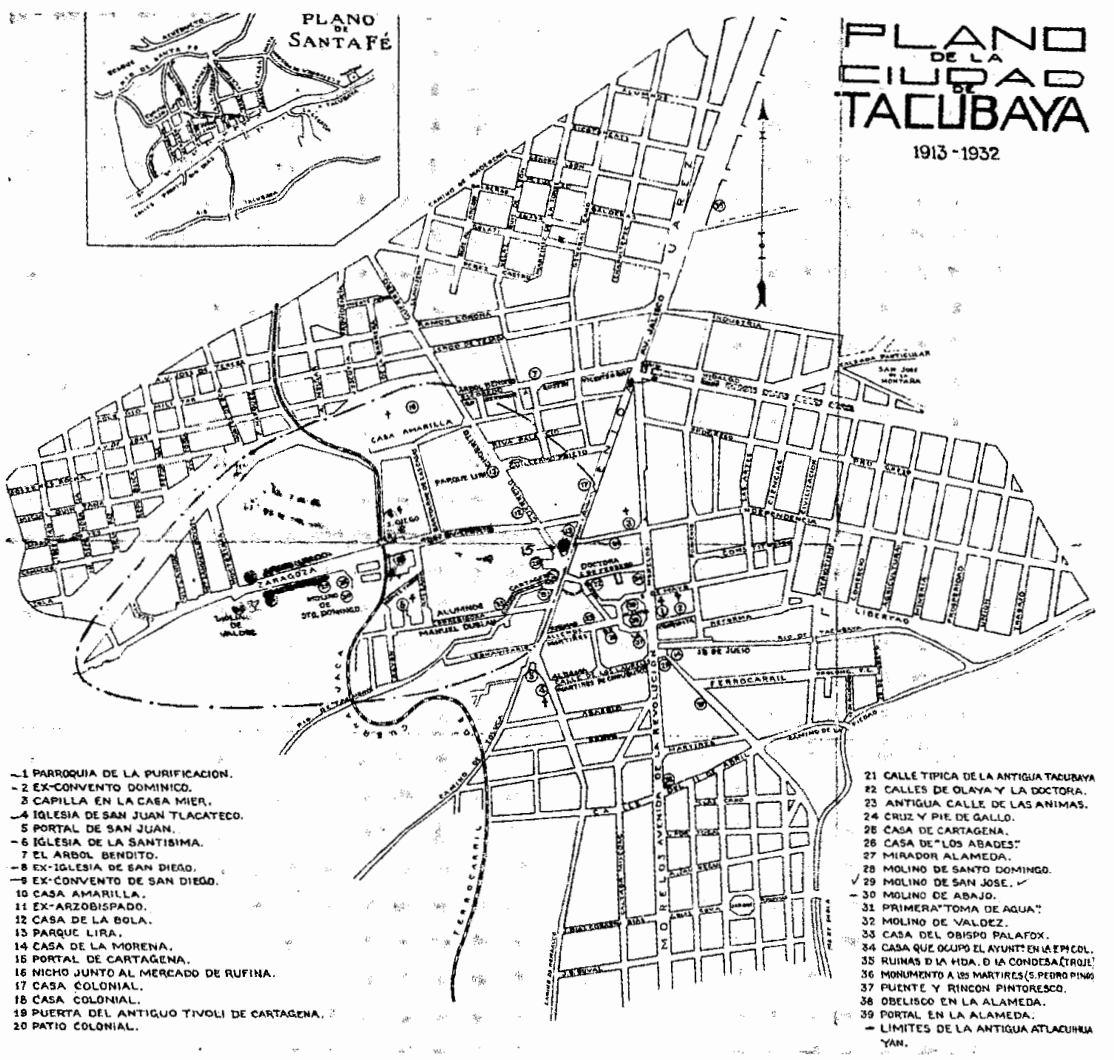


positivismo, la electricidad era uno de los símbolos más evidentes del progreso y de la modernización, y su introducción en el país significaba también el ingreso de México al rubro de las naciones "civilizadas" y "cultas", como Francia, Alemania o Inglaterra, que tanto se admiraban en el porfiriato. La proximidad de las fiestas del Centenario darían a Díaz el pretexto y la oportunidad de poder exhibir al mundo los logros a los que el "orden y el progreso" habían conducido a este país, y por ello esta energía se convertiría, de alguna manera, en el símbolo de la ciudad, porque ella misma era el símbolo de la ciencia, del progreso y de la civilización, y la de México tenía que pasar por una urbe científica, progresista y civilizada, sólo así sería moderna, estaría "a la moda", acorde con el nuevo siglo y la nueva era que empezaba.

$Y$ es justo cuando hacemos un recorrido por los progresos que se fueron haciendo en la extensión, cobertura y despliegue del alumbrado en las diferentes fiestas nacionales que podemos constatar el significado que se le dio a esta casi mágica fuente de energía. Se continuaba, además, con esta expresión lumínica, la costumbre ancestral de dotar a las celebraciones de una luz especial, tradición presente en la historia de casi todas las sociedades, para lo cual se han utilizado desde antorchas hasta fuegos artificiales, asociando la iluminación con lo relevante o lo destacado. Así pues, la electricidad daba la oportunidad de alumbrar de manera feérica, nunca vista hasta entonces, una fiesta nacional.

Para el caso de las fiestas septembrinas, un recorrido por la forma en la que se festejó la independencia en este periodo nos permite observar claramente la mo- dernización que fue llevando la ciudad y la forma en la que, año tras año, se vestía de fiesta y engalanaba con miles de lámparas. Así lo hizo durante los años que cubre el porfiriato, con la diferencia de que cada vez se aumentaban unas cuantas luces a las ya existentes, se ampliaba el perímetro alumbrado y se renovaba la instalación con los últimos adelantos de la ciencia y la tecnología: se fueron cambiando los postes por columnas de hierro estilizadas, a los cables -antes "pelones"se los recubrió con una capa de material aislante para hacerlos más seguros $y$, donde se pudo, se realizaron instalaciones subterráneas.

Llegó a ser tal la expectación generada a propósito del adorno de la ciudad con focos eléctricos que los edificios públicos y diferentes casas comerciales como droguerías, joyerías, restaurantes o almacenes -símbolos también de la ciudad moderna que se construía, por cierto- competían por llamar la atención de la población capitalina, por ganar el reconocimiento como la mejor alumbrada.

Lograr la iluminación deseada fue un proceso paulatino que implicó desde hacer los primeros ensayos con energía eléctrica hasta conseguir la cobertura total. Año tras año se fueron haciendo avances importantes en su extensión y utilización, y en este proceso hubo ocasiones en las que se podían encontrar en la ciudad las diferentes formas de iluminación utilizadas en nuestra historia y que incluían descle el uso del ocote, el aceite y la trementina, hasta el gas y la electricidad. De hecho, estas últimas dos fuentes de energía se introdujeron en el país casi de manera simultánea, con poco tiempo de diferencia, siendo por muchos años las lámparas de gas las más apreciadas, incluso existiendo ya 
las eléctricas. Poco a poco, sin embargo, terminarían por imponerse estas últimas.

$\mathrm{Al}$ parecer, la primera gran fiesta que se realizó con luz eléctrica a borbotones fue en diciembre de 1900, cuando coincidió la celebración de la quinta reelección de Díaz con el inicio del nuevo siglo. Para la ocasión, la ciudad se vistió con cientos de focos incandescentes que formaban banderas, flores y estrellas, siendo "la iluminación más notable [...] el retrato del señor presidente de la república, que coronaba el edificio rodeado de luces tricolores y teniendo como detalles estrellas colocadas en las paredes". ${ }^{12}$

No sería fortuito, desde luego, que la figura de Díaz fuera la que llamara más la atención de la población, como tampoco lo era que se aprovechara esta nueva tecnología para iluminarla; por el contrario, se dejaba así constancia del significado que tenía la electricidad y también de la responsabilidad que el presidente tenía en su despliegue y derroche por toda la capital. En adelante, serían las fiestas patrias las que servirían de escaparate cotidiano para constatar los avances de la red eléctrica por la ciudad, ${ }^{13}$ en un proceso curioso en donde los progresos en la instalación eléctrica fueron de la mano del paso de Díaz por la presidencia de la

${ }^{12}$ El Imparial, 2 de diciembre de 1900.

${ }^{13}$ Vale la pena recordar que, tras su manifestación en forma de alumbrado, la electricidad requirió de fuertes inversiones, de la construcción de una infraestructura muy importante, de la importación de una gran cantidad de material y aparatos, del aprovechamiento de cientos de trabajadores, de la alteración del paisaje rural y urbano, de los inconvenien tes que la colocación de postes, cables o generadores provocaron en las calles, y de las molestias a los vecinos, entre otras muchas consecuencias. república, como si uno y otro se complementaran, y uno y otro dieran sentido y justificación a su existencia.

\section{LAS FIESTAS PATRIAS O "LAS FIESTAS DE DON PORFIRIO"}

Si bien desde 1881 se realizaron los primeros ensayos con la colocación de doce focos eléctricos, la idea de festejar el 15 y 16 de septiembre se volvió más sofisticada conforme se consolidaba la presencia de don Porfirio en el poder y se empezaban a mostrar visos de progreso en la ciudad. ${ }^{14}$ Aunque se habían hecho algunos intentos anteriormente, fue hasta 1889 cuando se dio la pauta para llenar de luz estas celebraciones, pues en este año se iluminaron por primera vez las torres de la catedral con cientos de focos eléctricos al momento del "grito".

Poco a poco, la costumbre de dar luz a las fiestas patrias se convirtió en una tradición que ha perdurado hasta nuestros días, sin embargo, las celebraciones se convirtieron en algo realmente apoteósico a partir de 1893, cuando además de la iluminación en la catedral y los palacios Nacional y Municipal se vistieron con luces tricolores la mayoría de los edificios y casas de comercio capitalinas, como la Droguería Labadie y el edificio de las Fuerzas Hidroeléctricas de San Ildefonso. Para esta ocasión se llevó a cabo también

${ }^{14}$ Enrique Plascencia afirma que la costumbre de celebrar la independencia el 15 de septiembre por la noche tuvo lugar en 1854 haciéndola coincidir con el estreno del himno nacional. Sin duda que Porfirio Díaz capitalizaría a su favor esta circunstancia, pero no fue responsable de su existencia. Véase Plascencia, Independencia, 1991. 
un desfile de carros alegóricos, en el que resultó significativo el hecho de que fuera el de la Compañía Mexicana de Gas y Luz Eléctrica el primero en desfilar, en una franca alusión a su importancia en el desarrollo nacional, el progreso y la modernización alcanzada ${ }^{15}$ En su decoración se "representaba la electricidad por una estatua de mujer plateada y sentada sobre un caldero de vapor. En la mano de la estatua se veía una especie de cetro despidiendo rayos". ${ }^{16}$

$\mathrm{Al}$ año siguiente, la novedad sería la casa del señor Knight -representante de la Compañía Mexicana de Gas y Luz Eléctrica, ubicada en la 1a. calle de San Francisco- ${ }^{17}$ que representaría un gigantesco cometa con una gran cauda de diez metros de longitud y cuyo núcleo era una estrella giratoria. En total la decoración de esta figura contaba con 200 luces incandescentes, toda una hazaña para la época por lo que respecta a su diseño, distribución y sincronización.

Los progresos se fueron haciendo evidentes año con año. En 1896 se colocó la campana de Dolores sobre el balcón prin-

${ }^{15}$ El alumbrado público era una de las arribuciones del Ayuntamiento de México, que era el órgano que otorgaba las concesiones del servicio y se encargaba de supervisar el funcionamiento del ramo. Para mayor información véase Rodríguez, Experiencia, 1996.

${ }^{16}$ El Monitor Republicano, 17 de septiembre de 1893.

${ }_{17}$ Sin duda, Plateros y su continuación en San Francisco se consolidarían durante esta época como las calles más populares, e incluso adquirieron el nombre de bulevares, en una franca alusión e imitación de los bulevares parisinos concebidos por Haussman. En ellas se establecerían algunas de las principales casas comerciales de la capital. cipal de Palacio, la cual se iluminó súbitamente a las 11 de la noche, arrancando -según las crónicas- un sonoro rumor entre los presentes que ahogaron así el sonido de los dos toques que le dio Díaz. De manera paralela a la electrificación, estas manifestaciones se aprovechaban para que el discurso oficial se fuera consolidando en el sentido de reforzar el nacionalismo y de recuperar la confianza en el porvenir en un año clave para la historia nacional, pues la Hacienda pública mostraba ya un superávit en sus finanzas.

Los porfiristas iban conformando así -en algunos sectores- la imagen de país que habían proyectado construir. México daba una nueva faz al mundo, asumía costumbres europeas, recibía grandes inversiones, tenía un importante desarrollo económico y daba un impulso inédito a la construcción de infraestructura. Como parte de esta última, la electricidad se iba convirtiendo en una de las piezas maestras del rompecabezas para los porfiristas, quienes parecían impulsar la idea de que progreso y grado de iluminación fueran de la mano.

Congruente con este discurso, en los edificios públicos se magnificaba la imagen de Díaz formando su silueta aquí y allá, logrando que, a la par que se extendía el alumbrado y se exacerbaba el espíritu patriótico de la población, se afianzaba el nacionalismo y la veneración a la figura del presidente. En su conjunto, la profusión en el alumbrado llevaría además a miles de visitantes a la ciudad, deseosos de ser testigos del nuevo paisaje nocturno y del milagro de ver a su capital convertida en una metrópoli similar a las de Europa, con iluminación eléctrica, casas, bulevares y avenidas, todas al más puro estilo francés. 
Para 1899 muchas casas comerciales y particulares deseaban sumarse a esta fiesta de luz adornando sus fachadas con focos, sin embargo, el suministro fue insuficiente. Se hizo entonces necesario invertir en plantas generadoras de electricidad, capaces de satisfacer las exigencias de una capital que crecía a ritmo acelerado y en la cual la electricidad era necesaria, ya no sólo para el alumbrado público y la industria, sino también para las casas habitación que introducían este servicio así como los diversos aparatos que requerirían de esta energía -como elevadores, planchas, ventiladores o aspiradoras. ${ }^{18}$

En un lugar no menos importante se haría indispensable también su uso para las exigencias que la recién inventada vida nocturna empezaría a demandar en los teatros, restaurantes, bares, cafés o tertulias, entre otros.

Pero 1899 tendrá una peculiaridad más en esta historia de las celebraciones de las fiestas patrias durante el porfiriato, y es que, en este año, los periódicos se refirieron a éstas como las que se realizaban en honor del "primer magistrado de la república", colocando en segundo término al festejo de la independencia y dejando con ello muy claro cuál era el sentido que se le quería agregar a la celebración: hacer un reconocimiento público a la figura de Díaz.

El país se encontraba en la antesala del nuevo siglo, y en él se vislumbraba un futuro prometedor para esta nueva fuente de energía que daba ya muestras claras de su potencial. Quizá por ello, de

\footnotetext{
${ }^{18}$ Estos últimos aparecen en la literatura como abanicos y escobas eléctricas. Para el caso de los ventiladores existen referencias en donde las personas jugaban con ellos una especie de ruleta, aprovechando el giro de las aspas.
}

nueva cuenta el carro alegórico de la electricidad presidió el desfile, representando, según refirió El Imparcial:

Un gran globo terrestre flotando entre nubes tenues formadas de gasa de plata. Sobre el mundo las ruedas del progreso y sentada en ella una joven morena, mórbida, bien formada, llevando un gran foco sistema Edison en una mano, representación de la electricidad. [...] Al frente del carro una niña, Refugio Zúñiga, coronaba con un gran laurel circular los bustos de Siemens y Edison. En el centro de la alegoría había un dinamo eléctrico. ${ }^{1.9}$

Focos y dinamos que adquirían una belleza digna de ser representada en un desfile de carros alegóricos dando paso, a la vez, a una nueva percepción de la estética en donde hasta los aparatos tecnológicos e instalaciones eléctricas resultaban "bellas".

Como hemos dicho, el cambio de siglo no defraudó a nadie en cuanto a iluminación de la capital, y para las fiestas patrias de 1900 "la ciudad en general era un reguero de luces de brillantes colores, un manto de claridad que se extendía por todas partes" ${ }^{20}$ Desde el año anterior, el Ayuntamiento había anunciado que la capital se encontraba totalmente iluminada por focos eléctricos, lo que daba una nueva apariencia a la ciudad, más uniforme y brillante que los años anteriores, acorde con el nuevo siglo que empezaba. ${ }^{21}$

${ }^{19}$ El Imparcial, 16 de septiembre de 1899.

${ }^{20} \mathrm{Ibid}$. 16 de septiembre de 1900 .

${ }^{21}$ Aunque se publicitó mucho el que la ciudad de México se encontraba plenamente alumbrada con energía eléctrica, las actas de Cabildo de años posteriores a 1900 hacían constantes referencias a las lámparas de gas. 
Así fue que, año tras año, la capital se adornaba especialmente para las celebraciones cívicas y las navidades. Año tras año, también, se fue incrementando la potencia eléctrica generada, crecieron sus aplicaciones y se extendió el alumbrado gracias a las jugosas inversiones que se realizaron en el ramo durante este periodo y que ascendieron a cerca de 150000000 de dólares. El costo -económico, político $\mathrm{y}$, sobre todo, social- de estas inversiones, pareció subestimarse ante un proyecto tan ambicioso como el que se pretendía; la mira, como hemos dicho, se encontraba puesta en las fiestas de 1910 y mucho del progreso deseado parecía reducirse en una sola palabra: electricidad. Los beneficios que se obtendrían justificaban, quizá, los graves problemas por los que atravesaba el país, mismos que el resplandor capitalino no logró disipar.

\section{0: UN ESTALLIDO DE LUZ}

A pesar de los problemas que el país enfrentaba y de algunos signos de alarma que de manera más o menos constante aparecían aquí y allá, la preparación de los festejos del Centenario de la Independencia no se interrumpió. La modernización de la capital se planeó con bastante anticipación y contempló el embellecimiento general de la ciudad: desde la construcción de diversos edificios públicos hasta el arreglo de calles y avenidas o la inauguración de monumentos que glorificaran el pasado. ${ }^{22}$

22 Sólo en la primera quincena de septiembre de 1910 se llevaron a cabo las siguientes inauguraciones: el hospital de la Castañeda, el monumento a Alejandro von Humboldt en lả Biblioteca Nacional, la Es-
Los diarios, por su parte, se encargaron a su vez de preparar los ánimos y elevar las expectativas de la población ante este hecho tan singular, en particular El Imparcial, periódico porfirista que dedicó largos editoriales antes, durante y después del evento, exaltando de manera especial el alumbrado que luciría la capital en la celebración de las próximas fiestas patrias. En sus páginas no era raro encontrar afirmaciones como la siguiente:

La iluminación de la ciudad de México durante el próximo mes será, de hecho, una de las más elocuentes demostraciones del progreso de este maravilloso país durante los últimos cien años. Al recorrer estas calles brillantemente iluminadas, no hay que olvidar que desde aquella hora memorable en que el patriota sacerdote Hidalgo tocó la campana que había de señalar los futuros destinos de México, hasta la hora actual, la mayor parte del progreso de ésta y otras grandes naciones del hemisferio Occidental se ha debido a ese misterioso poder que tan liberalmente será empleado durante la celebración del Centenario. ${ }^{23}$

$Y$ en efecto, las diversas crónicas, películas y fotografías muestran y dan fe de la gran expresión lumínica que se logró

tación Sismológica, el tearro de la Escuela Nacional Preparatoria, el nuevo edificio para el Ministerio de Relaciones Exteriores y otro para el de Defensa, y la Escuela Normal de Maestras. De manera paralela se inauguraron diferentes exposiciones de arre e industria de España, de productos japoneses y de arte mexicano de vanguardia. También se llevaron a cabo el Congreso Internacional de Americanistas, el $4^{\circ}$ Congreso Médico Nacional y el Congreso Pedagógico de Instrucción Primaria. Véase Tenorio, "1910", 1996, p. 77.

${ }^{23}$ El Imparcial, 28 de agosto de 1910. 


\section{SECUENCIG}

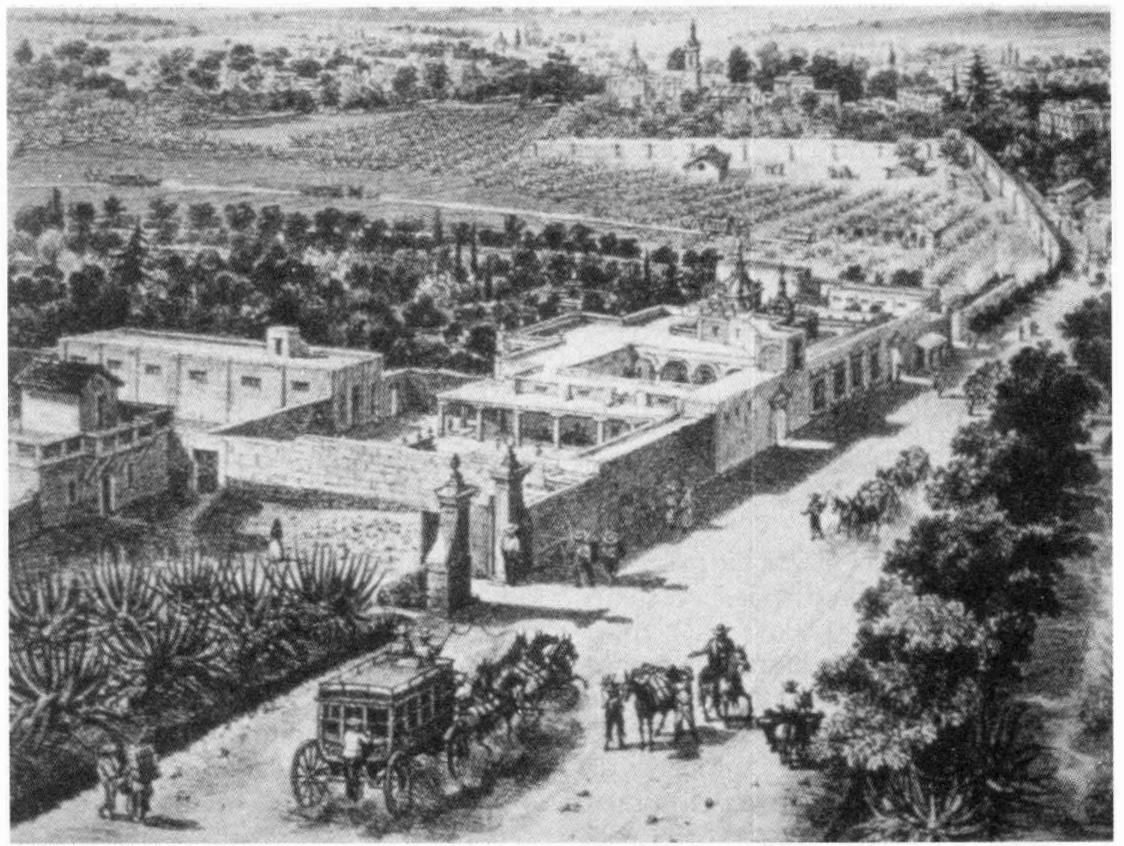


entonces. En ellas se alcanza a ver claramente cómo la capital brilló en aquel septiembre como nunca antes, tanto por la extensión del alumbrado, como por la dimensión que adquiría el festejo de la independencia en este emblemático año.

La ciudad brilló también por la calidad y cantidad de invitados especiales que visitaron México -confiriéndole la jerarquía de una verdadera capital cosmopolita- y por la magnitud ornamental de los monumentos y edificios inaugurados para la ocasión, todos ellos presididos por la Columna de la Independencia, que presumían estaría iluminada las 24 horas del día gracias a la luz solar y a la electricidad.

El fin era que toda la ciudad se viera iluminada, y para ello hubo una comisión encargada de que los edificios públicos, las calles y fachadas de la capital estuvieran a la altura de los festejos. La idea era que todo saliera de lo común y alcanzara los límites de la grandiosidad, que todo fuera una verdadera "ascua de luz", como se dijo entonces.

Para lograrlo, la planta hidroeléctrica de Necaxa ${ }^{24}$ puso a disposición de los consumidores 10000 kilovatios, la máxima energía producida hasta ese entonces para iluminar la capital. Y si para este año ya se presumía que la ciudad de México era una de las mejor iluminadas del mundo -tomando en cuenta el número de bujías por metro cuadrado y el perímetro que abarcaban - todo eso no sería nada comparado con el despliegue de luz que se lograría, sumando a los focos ya

\footnotetext{
${ }^{24}$ La planta hidroeléctrica de Necaxa empezó a enviar energía a la capital en 1905, pero su máximo poder de generación lo alcanzaría para las fiestas del Centenario.
}

existentes, 250000 más para alcanzar un total de 1000000 de lámparas.

El esfuerzo realizado por los capitalinos se vería coronado con creces cuando se logró que en las noches septembrinas pareciera como si la ciudad se debatiera "en la angustia de un incendio, pues la luz corre, se extiende, inunda y se eleva dorando el horizonte con matices de llama". ${ }^{25}$ Muchos comercios vistieron "ropajes de luz" para la festividad y cada uno de ellos compitió en elegancia, belleza, diseño y resplandor de su iluminación. La fábrica de cigarros El Buen Tono desplegaría en su fachada una gigantesca águila, por lo que se convirtió en uno de los recintos más admirados de las fiestas por su arte, buen gusto y esplendor. En general, todos los edificios ayudaron a crear un espectáculo fantástico - ¿fantasmagórico quizá para algunos?- de la capital, gracias a un avance tecnológico que consistió en tiras de cable a las que venían ya soldados los sockets, esto facilitó la colocación, la distribución y la armonía de los edificios. ${ }^{26}$

Las calles que contaron con el mayor alumbrado público fueron 5 de Mayo, San Francisco y 16 de Septiembre, pero en cada cruce o bocacalle había arcos con focos tricolores, siendo el principal aquel que se colocó en la intersección del Zócalo y Plateros. Asta banderas luminosas y figuras simbólicas se distribuyeron estéticamente por la ciudad, mientras que los mercados de la Iagunilla, la Merced, Santa Ana, San Juan, San Cosme, San Lucas, Dos de Abril y Martínez de la Torre gozarían de alumbrado especial.

${ }^{25}$ El Imparcial, 6 de septiembre de 1910.

${ }^{26}$ Ibid., 28 de junio de 1910. 
Las casas comerciales, tiendas departamentales y centros de reunión no se quedaron atrás, entre ellos destacaron la iluminación de la Gran Sedería, el Puerto de Veracruz, las Fábricas Universales, el Centro Mercantil, la Francia Marítima, el Palacio de Hierro, la Corsetería Francesa, el Banco Mexicano de Comercio e Industria, la Droguería Grisi, la casa Boker, la pastelería El Globo, los teatros Principal y Colón, el Círculo Católico, el Casino Francés, el Centro Asturiano, el Casino Espanool, ${ }^{27}$ el Hotel Sanz y la joyería La Esmeralda, así como las casas de las familias Cervantes, Braniff y De la Torre, entre otras. Por si esto fuera poco, la Compañía Mexicana de Luz y Fuerza Motriz ${ }^{28}$ facilitó lámparas de manera gratuita para el adorno de las viviendas a la población que así lo solicitara, ${ }^{29}$ y ella misma realizó unas instalaciones espléndidas en su edificio. No en balde era también la representante del progreso.

${ }^{27}$ El Centenario coincidiría con las fiestas de Covadonga en el mes de septiembre, para ello, la colonia española organizó corridas de toros y kermeses, y transformó el parque español de Covadonga para que en el hubiera celebraciones todas las noches desde el día 4 hasta los últimos días del mes. Ibid., 18 de agosto de 1910.

${ }^{28}$ Para la prueba de la iluminación del edificio de esta compañía hubo invitados especiales a los que, una vez realizada con éxito la exhibición, se les invitó un ltuch-champagne, en donde H. D. Hutchinson y James Carson fueron los anfitriones. Tanto el ambigú como los nombres dan idea de la influencia extranjera en la empresa y, por ende, en la economía del país.

29 "Para el Centenario, lámparas gratis. ¿Piensa ud. decorar su casa en honor de la gran celebración? En tal caso usted puede conseguir las lámparas necesarias enteramente gratis." El Imparcial, 20 de julio de 1910.

LA FIESTA de LUZ EN la CIUdAd dE MÉXICO
La catedral, por su parte, fue una de las piezas clave del escenario y la más iluminada con diez lámparas de arco y 16000 focos incandescentes, el doble de los que tendría el Palacio Nacional, haciendo evidente el peso y la jerarquía de la Iglesia entre los mexicanos. En sus torres, profusamente iluminadas, destacaban las palabras libertad y progreso, al calce de las cuales se podían distinguir, respectivamente, las figuras de Hidalgo y de Díaz, haciendo alusión a lo que cada uno de ellos significaba; si Hidalgo simbolizaba la libertad, Díaz lo menos que podía encarnar era el progreso, un progreso que se reflejaba con todo el esplendor que la luz eléctrica daba a la ciudad; luz que, por cierto, también se erguía como un símbolo del mismo, pues, qué mayor adelanto que mostrar al mundo, a través del derroche de electricidad, lo mucho que se había logrado en el porfiriato. En medio de ambas torres, en el lugar del reloj, aparecía la palabra paz, resaltando evidentemente lo que Díaz quería destacar: libertad, progreso y paz. ${ }^{30}$

Así, la noche del 15 de septiembre de 1910 los capitalinos y los invitados especiales para la ocasión -representantes de diversos países- presenciaron en el centro de la ciudad de México lo que fue quizá uno de los espectáculos más impresionantes que se pudieron haber realizado en cualquier parte del mundo para esos años, en el cual convivieron arraigadas costumbres con un despliegue impresionante de tecnología moderna, tal y como lo refirió entonces Federico Gamboa:

Y pausadamente, el reloj del Palacio y el de la catedral rompen juntos ese silencio; pri-

${ }^{30}$ Ibid., 16 de septiembre de 1910. 
mero con cuatro campanadas lentas - los cuatro cuartos de hora-, después con once, que nacen con idéntica lentitud mecánica. No bien han nacido, cuando todo a un tiempo, se enciende el balcón histórico, el de barandal de bronce, y dentro de un óvalo de rayos eléctricos, surge el presidente de la república, símbolo en medio a tanta claridad. ${ }^{31}$

Pero las fiestas guardaban aún lo mejor en materia eléctrica, y es que la intensidad de la luz se fue dosificando y entregando a cuentagotas a los observadores en un afán de hacer más espectacular el momento climático. Para el 5 de septiembre se había encendido una sección de la iluminación; la mayor parte se prendió en la noche del 15, pero se quiso desplegar su totalidad hasta el día 19, cuando el presidente ofreció un baile en el Palacio Nacional e hizo que sus salones estuvieran alumbrados como nunca antes lo había estado ningún otro recinto en el mundo. ${ }^{32}$

Según las crónicas, habría en el edificio 40000 lámparas incandescentes y más de 100 lámparas de arco. Además, para evitar el tráfico, las aglomeraciones y las molestias a los dignos asistentes al baile, se usó un nuevo invento, un tablero indicador de dos caras. Los invitados daban el número de su carruaje o automóvil a un sirviente para que lo transmitiera por teléfono a un aparato eléctrico colocado frente al Palacio, donde aparecería el

${ }^{31}$ Gamboa, Santa, 1979, p. 98.

${ }^{32} \mathrm{La}$ comparación tiene que ver con la celebración en Nueva York del centenario de la navegación de vapor que se realizó con un gran baile iluminado profusamente. Para el reportero, el Palacio Nacional superaba ahora a aquella exhibición. El Imparcial, 12 de agosto de 1910. número que, al ser visto por el cochero, procedería a recoger a quienes lo habían llamado. Automóviles, tableros eléctricos, teléfonos, era la tecnología en su máxima expresión.

En lo alto de la ciudad, Chapultepec lució radiante también, mientras que sus árboles y aguas "centellearían" alumbradas por miles de focos. Asimismo, el Palacio Cobián de la calle de Bucareli, donde se alojó la delegación estadunidense, lució una iluminación espectacular. En general, el alumbrado alcanzó su apoteosis entre los días 12 y 20 de septiembre y entre las seis de la tarde y las doce de la noche, horas durante las cuales se mantuvo encendido.

Prácticamente todos los periódicos y crónicas de la época dieron noticia de la explosión de luz que caracterizó, por sobre todo lo demás, a las celebraciones del Centenario. Fue lo más sobresaliente de los festejos, por encima de las obras públicas u ornamentales, más allá de otros trabajos de infraestructura como asfaltado, instalaciones hidráulicas o el desarrollo de nuevas colonias. Fueron unos días en los que las calles, los edificios, los monumentos, los comercios, los aparadores y las casas particulares se iluminaron como nunca antes en la historia de este país.

Muchas lecciones dejó a los mexicanos y extranjeros la explosión de luz durante la celebración del Centenario de la Independencia. Una, quizá la más sobresaliente, la necesidad, casi obsesiva, de mostrar un país donde había de más: más progreso, contundente en el uso y abuso de la electricidad. Dos, que la manifestación de esta energía, por medio del alumbrado, dejaba constancia de que su presencia en México era real, que ésta era quizá la ciudad mejor iluminada del mundo y, por 
ende, la que tenía mayor potencial. Tres, que la electricidad representaba la fuerza que movía, en sentido literal y figurado, los motores de la industria, en un mundo que hizo de las máquinas su monumento y emblema y que se traducía en progreso. Cuatro, que en consecuencia México tenía todo para ser una potencia igual o mejor que las extranjeras. Cinco, que Díaz era el artífice de este prodigio y como tal tenía que ser reconocido y señalado, y aparecer tal y como lo hacía su figura en la torre de la catedral, como sinónimo de progreso.

Congruente con esta imagen que se pretendió dar, Federico Gamboa escribió en su Diario, apenas unos días después de las fiestas:

El espectáculo que ha ofrecido el reciente Centenario ha puesto de bulto lo que vale y significa la obra titánica que Porfirio Díaz ha consumado en su país, el grado a que logró prestigiarlo, el concepto en que el mundo que cuenta tiene hoy por hoy a nuestro México. ${ }^{33}$

\section{0: EL OLVIDO}

No obstante todo el esfuerzo realizado por dar una apariencia de modernización y refinamiento a este país, los severos conflictos sociales, económicos y políticos por los que atravesaba México terminarían por neutralizar y, quizá, dejar en el olvido esta significativa fiesta nacional, pues apenas unos días después estallaría la revolución. Para entonces, muchos mexicanos habían aprendido a beneficiarse con la

${ }^{33}$ Gamboa, Diario, 1977, p. 69. La referencia corresponde al 1 de octubre de 1910. electricidad y temían, incluso, que el brote de violencia pudiera afectar las plantas generadoras. $\mathrm{Y}$ es que, si en un primer momento la energía eléctrica despertó temores $^{34}$ entre la población, para 1910 sus ventajas estaban plenamente demostradas y sus aplicaciones iban en ascenso. Lo que se temía, entonces, era que la oscuridad ensombreciera aún más el panorama que los mexicanos vislumbraban.

Los temores fueron infundados, pues al menos en el caso de la planta hidroeléctrica de Necaxa, ésta no fue atacada por los revolucionarios, lo que permitió que la ciudad de México continuara siendo una de las mejor iluminadas del planeta.

Tampoco se apagaría la costumbre de celebrar el 15 y 16 de septiembre con un gran derroche de luz, pero en adelante, el significado de la celebración poco recordaría a aquel 1910, al Centenario o a la figura de Díaz. También quedaría en el olvido, quizá, la referencia a esta ciudad de México como la ciudad moderna que quiso ser y que, al menos por unos días de aquel mes de septiembre, consiguió serlo.

La revolución mexicana, que estallaría apenas unos días después, daría al traste con esta imagen de esplendor y brillo que

${ }^{34}$ En un principio, la población fue escéptica en torno a la sustitución del alumbrado de gas por el eléctrico, al cual no conferían grandes ventajas. Además, los accidentes provocados por las descargas eléctricas propiciaron un gran temor entre la sociedad que veía con alarma cómo la gente moría calcinada o sufría quemaduras graves como consecuencia de una fuerza desconocida e intangible, que parecía, incluso, diabólica. No era extraño encontrar referencias a estos accidentes en los siguientes términos: "las señales de las quemadoras le quedaron en la frente y el cuello como extraños paisajes, dibujados como con una piedra infernal". El Monitor Republicano, 5 de noviembre de 1884 . 


\section{SECUENCIA}

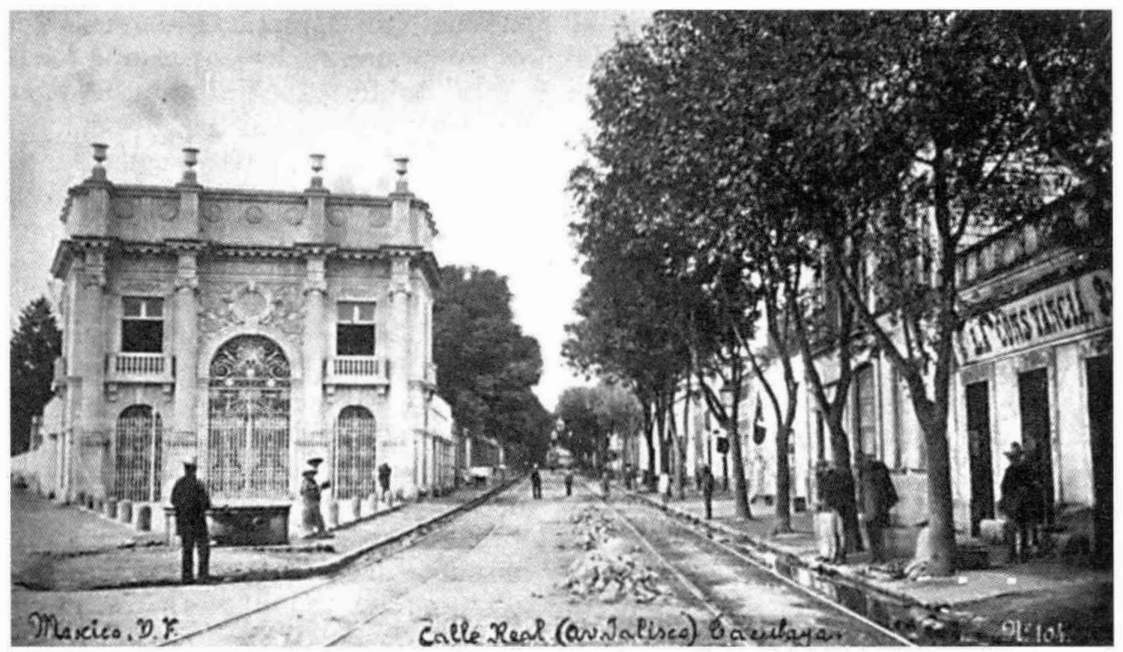


el gobierno porfirista se había esmerado en construir, como un recurso que le permitiera deslumbrar, con su resplandor, la mirada de propios y extraños, evitando así que el mundo constatara la cruda realidad social que se escondía tras esa expresión mágica de la ciencia y el progreso.

No obstante, sería injusto concluir que las obras y la inversión en infraestructura durante el porfiriato fueron nada más que un relumbrón. Una visión equilibrada de ese periodo debe reconocer que, si bien el costo social del progreso alcanzado fue muy alto, las inversiones fueron también indispensables para lograr la integración geográfica y política del país, así como para mejorar las condiciones económicas de México. En ese esfuerzo, la electrificación sería una de las piezas clave y desempeñaría un papel fundamental como impulsora de la industria, mientras que en su aplicación al alumbrado público y privado daría lugar a una nueva vida cotidiana en la que sobresaldría, sin duda, la invención de la vida de noche y de los espacios nocturnos. $^{35}$

\section{HEMEROGR AFÍA}

El Imparcial, 1896-1913.

El Monitor Republicano, 1880-1896.

\section{BIBLIOGRAFÍA}

-Actas de Cabildo del Ayuntamiento Constitucional de México, 1893-1903, edición de El Municipio Libre, Imprenta de la Escuela Correccional de Artes y Ofícios, México, 1904.

${ }^{35}$ Para ubicar la trascendencia de la electricidad en el siglo que apenas empezaba, véase Cazadero, $R e$ voluciones, 1987.

LA FIESTA DE LUZ EN LA CIUDAD DE MÉxICO
-Agostoni, Claudia y Elisa Speckman (eds.), Modernidad, tradición y alteridad. La ciudad de México en el cambio de siglo (XIX-XX), UNAM, México, 2001.

-Arizpe, Rafael, El alumbrado priblico en la ciudad de México, Tipografía y Litografía La Europea, México, 1900.

-Briseño S., Lillian, "Lo particular y lo social en el porfiriato. La vida diaria en la ciudad de México. 1877-1911", tesis de doctorado, UNAM, México, 2002.

-Bowers, Brian, Lenghtening the Day. A History of Lighting Technology, Oxford University Press, Unites States, 1998.

-Campo, Ángel de, La semana alegre, Tick Tack, incr. y recop. Miguel Ángel Castro, UNAM, México, 1991.

-Carranza Castellanos, Emilio, Crónica del alumbrado de la ciudad de México, Nueva Dimensión Gráfica, México, 1991.

-Cazadero, Manuel, Las revoluciones industriales, FCE, México, 1987.

-Ceseña, José Luis, México en la órbita imperial, las empresas trasnacionales en México, El Caballito, México, 1973.

-Cuéllar, José Tomás de, Los fuereños, Imprenta y Litografía de El Atlántico, Santander, 1890.

1999.

-Frías, Heriberto, Los piratas del Boulevard, Andrés Botas, México, s. a.

-Galarza, Ernesto, La industria eléctrica en México, FCE, México, 1941.

-Gamboa, Federico, Diario de Federico Gamboa, 1892-1939, selección, prólogo y notas de José Emilio Pacheco, Siglo XXI, México, 1977. ___, Santa, Grijalbo, México, 1979.

-González Peña, Carlos, La chiquilla, Porrúa, México, 1987.

-Huarte, Ma. Concepción 'T., "La política de urbanización de nuevas áreas habitacionales 
en el porfiriato (1900-1910)", Fuentes, año 2, núm. 3, julio-diciembre de 1991.

-Moya Gutiérrez, Arnaldo, "Los festejos cívicos septembrinos durante el porfiriato, 1877 1910" en Claudia Agostoni y Elisa Speckman (eds.), Modernidad, tradición y alteridad. La ciudad de México en el cambio de siglo (XIX-XX), UNAM, México, 2001.

-Quirarte, Vicente, Elogio de la calle. Biografía literaria de la ciudad de México 1850-1992, Cal y Arena, México, 2001.

-Plascencia de la Parra, Enrique, Independencia y nacionalismo a la luz del discurso 18251867, Conaculta, México, 1991 (Regiones).

-Rodríguez Kuri, Ariel, La experiencia olvidada. El ayuntamiento de México: política y gobierno, 1876-1912, unam-Azcapotzalco/ColmEx, México, 1996.
-Tenorio Trillo, Mauricio, “1910 México Ciry: Space and Nation in the City of the Centenario", Journal of American Studies, The Cambridge University Press, núm. 28, 1996, Gran Bretaña.

-Wionczek, Miguel S., El nacionalismo mexicano y la inversión extranjera, Siglo XXI, México, 1975.

-Zárate Toscano, Verónica, "Las conmemoraciones septembrinas en la ciudad de México y su entorno en el siglo XIX" en Verónica Zárate Toscano (coord.), Política, casas y fiestas en el entorno urbano del Distrito Federal, siglos XVIII-XIX, Instituto Mora, México, 2003 (Historia Social y Cultural). 